\title{
Proposed Design of White Sugar Industrial Supply Chain System based on Blockchain Technology
}

\author{
Ratna Ekawati ${ }^{1}$ \\ Agro-industrial Engineering Graduate Students IPB \\ Staff Industrial Engineering Untirta \\ Cilegon, Banten, Indonesian
}

\author{
Yandra Arkeman ${ }^{2}$, Suprihatin $^{3}$, Titi Candra Sunarti ${ }^{4}$ \\ Agro-Industrial Engineering, IPB University \\ Bogor, West Java \\ Indonesian
}

\begin{abstract}
The white crystal sugar agro-industry is an industry with dynamic characteristics characterized by a sustainable relationship between actors ranging from farmers to consumers. An inefficient supply chain system will affect the flow of products, information, and finance because many actors are involved and have influence. Hence, complicating the system in the tracking process flow, product flow and creating problems that occur in business processes. The main objective of this research is to propose the design of an integrated white crystal sugar agro-industrial supply chain system based on blockchain technology so that it can increase competitiveness in realizing food security and resilience; by proposing a search for the problem of mismatches that occur along the supply chain from upstream to downstream. The variables that will be identified in the supply chain flow include quality, quantity, and price, with the suitability of transaction information data ranging from farmers, sugar factories, warehouses, distribution, retailers to the final consumer. It is hoped that consumers will feel happy to consume trusted local sugar with the best safety and quality, as well as ensure transparency of information between actors. Previous traditional methods, which were still centralized, would be transformed into decentralized information, to create trust among stakeholders. With a blockchain-based traceability architecture design, it is hoped that the proposed design can be implemented in the white crystal sugar agro-industry.
\end{abstract}

Keywords-Blockchain technology; supply chain; white crystal sugar

\section{INTRODUCTION}

White crystal sugar is one of the strategic commodities in the agricultural industry [1], therefore it is necessary to maintain both quality and quantity to achieve national food security and security. Quality improvement based on Icumsa 81-200 IU (SNI 3140.3: 2010), because the sugar produced during the milling period is not higher than $200 \mathrm{IU}$, causing waste in the production process.

The white crystal sugar agro-industry is an industry with dynamic characteristics characterized by a sustainable relationship between actors ranging from farmers to consumers. The low average efficiency of sugar mills based on plantation performance is $61.78 \%$ and factory performance $63.05 \%$ [2], the performance of sugar mills in Yogyakarta province is $72.338 \%$ [3], the performance of partner farmers is $75.86 \%$ [4]. Raw sugar production tended to decline over the last three years, in 2017 the production of raw sugar was only 2.21 million tonnes.
Sugar supply chain problems are very complex [5], [6], multi-stakeholder, long, high uncertainty, lack of coordination and integration, especially on the flow of data information distribution from farmers, factories. up to the consumer table [7], [8], [9]. This causes the end consumer not to have accurate and precise information regarding the quality and quantity of sugar. Because consumers only know that sugar is sweet, but do not know the meaning contained in the quality of the sugar, the difference in the color of sugar, and the shape of the grains on the market.

Inefficiency does not only occur in the main stakeholders but also occurs for supporting stakeholders such as associations that play a role and state institutions that play a role in monitoring the smooth running of production in terms of quantity and quality. So that sometimes power or wealth in terms of capital makes stakeholders strong who control data and game information in the sugar supply chain.

Less integrated product, financial and information flows can also affect supply chain performance [5]. Without coordination, it will be difficult to synergize data from upstream to downstream of the supply chain [10]. Therefore, an optimal, efficient and transparent supply chain system design is needed to improve the performance of business processes in the sugar agro-industry [9],[11], [12].

In the current era, supply chain problems also require traceability to be able to identify products, processes, and environmental characteristics, decision-making information, and overall system analysis [13], [14]. The development of the agro-industrial supply chain until the 5.0 era [15] was marketoriented, which had consumer feedback, and transparency about the quality, quantity, and process.

The proposed application of innovative technology is blockchain technology which has the characteristics of decentralization, immutability, reliability, and transparency. Blockchain technology records all data transaction information in each supply chain that can help and represent traceability assets [16], [17]. Digital product information such as details of agricultural origin, batch numbers, factory data and processing, expiration date, storage temperature, and delivery details are digitally related to food items and information at each step of the process [18]. 


\section{LITERATURE REVIEW}

Changes in business systems by applying technology can bring strong trust and transparency among supply chain actors in increasing added value and maximizing economic benefits [19], [20]\&[21]. In transactions between actors, so that the level of trust can be guaranteed, a new technology called blockchain is introduced, which is accompanied by a smart contract that contains rules or agreements for interacting. To avoid fraud and inaccuracy in payments, the distribution of data information between supply chain actors is created by creating an agreement between the actors who, if violated, will be given a penalty or sanction.

Agricultural products that have implemented blockchainbased on previous research are [22] proposed the application of blockchain to wine-based products with web-based RFID, [23] used a quantitative questionnaire for all actors involved in Burundi's coffee proposing blockchain technology based on the Technology Acceptance Model (TAM Hyperledger for Desktop Grain Controller (GDPA) Applications and GEBN Blockchain servers on grain products such as corn, soybeans, wheat in Brazilia apply digital blockchain contracts to all rice supply chain stakeholders in India, [24] applying the Ethereum blockchain and smart contracts for traceability of soybeans, [25] designed a blockchain business model that would help reduce logistics costs and optimize fresh vegetable supply chain operations, and proposed traceability to cocoa with digital watermarking [26].

Previous research is based on the study of Aung \& Chang (2014) [14] that traceability is closely related to safety, health, and quality in the food supply chain industry [17], Tian (2016) develops supply chains. blockchain verification system with RFID which aims to identify [27], monitor, and check the journey of industrial products across all actors. Galvez \& Mejuto (2018) blockchain is used to store data records with the role of sensors and IoT [28]. Blockchain according to Kamilaris et al. (2018) can build a reliable, transparent, and sustainable food supply chain environment, by integrating key stakeholders [29].

Following Fig. 1 below the research roadmap that will be carried out by researchers is based on previous reference papers regarding supply chain design, sugar supply chain, traceability, and blockchain technology. The researcher determined that the grand design of the study was a blockchain-based integrated white crystal sugar agroindustrial supply chain design technology that can increase competitiveness in realizing food security and resilience.

A search is carried out if there is a quality mismatch and an inaccurate amount of white sugar. Traceability of the sugar supply chain is carried out with stakeholders who play the main role based on the needs of each stakeholder from upstream to downstream. The technology that has been used and which will be used in the design of a supply chain system that aims to improve the performance of the sugar supply chain.

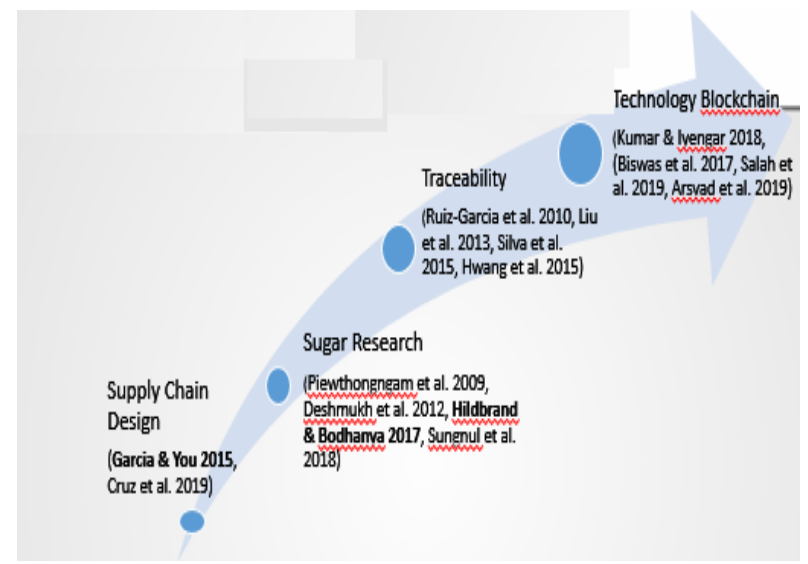

Fig. 1. Research Roadmap.

\section{METHODOLOGY}

The big objective of this research is to design an integrated white crystal sugar agro-industrial supply chain system based on blockchain technology that can increase competitiveness and realize food security and resilience. The steps in the flow of the research process are depicted in Figure 2. Several variables and data are used to produce research output. Data variables and supply chain systems from upstream to downstream are based on data in product flow, information flow to financial flow so that they become part of a decentralized blockchain consortium that uses smart contracts with the Ethereum platform.

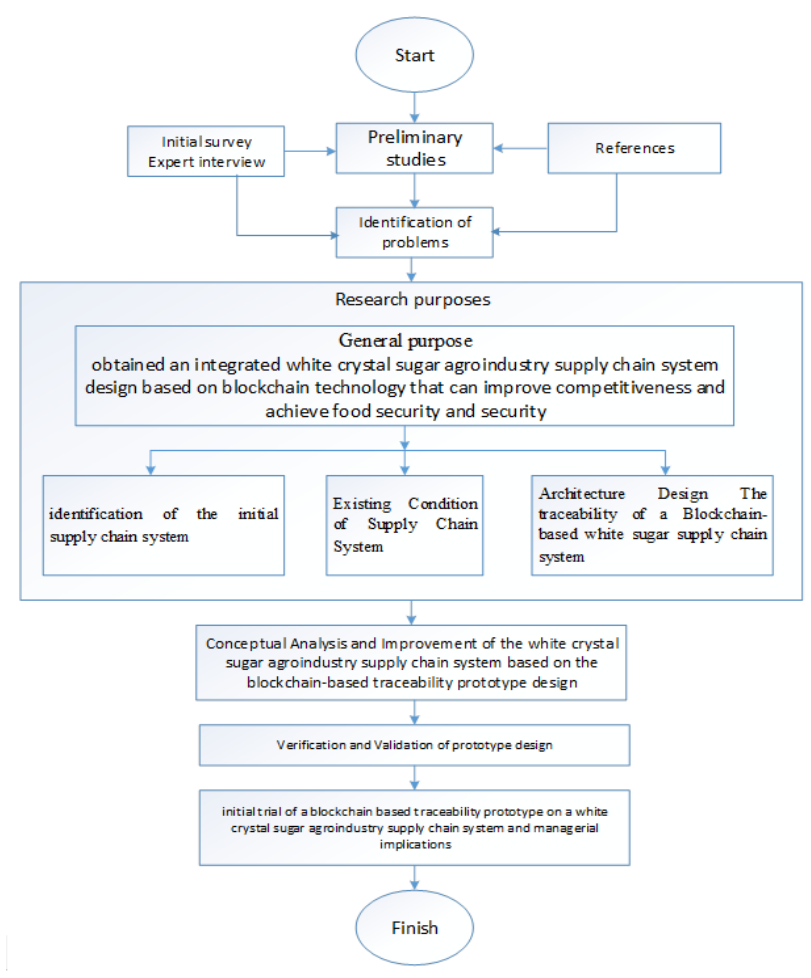

Fig. 2. Research Flow Chart. 
Etherium is a decentralized public blockchain network platform running smart contracts according to programming without any downtime or fraud. The blockchain work analogy that will be designed is that the actors participating in the supply chain system of the white crystal sugar agro-industry conduct or request transactions represented by each block, which will then be distributed to a peer network consisting of computers or nodes, where the nodes will validate the blocks and the transaction requested. If there are new transactions a new block will be created which will be added to the blockchain network and so on until the transaction is uploaded.

Specific objectives are stages to support the main objective in identifying the supply chain system of white crystal sugar agro-industry which consists of

- Identify the main factors influencing the flow of the supply chain and analyze their involvement such as farmers, factories, distributors, retailers, and consumers.

- Identify business processes and work activities that occur from upstream to downstream of the chain by collecting them based on literature reviews and also direct or indirect interviews based on preliminary surveys to sugarcane producing areas. The initial process of this identification will result in the supply chain system conditions of the existing white crystal sugar agro-industry.

- Identifying problem variables (critical) in the supply chain system of sugar agro-industry based on literature reviews, expert interviews (both from main actors and supporting actors regarding critical problems that often occur, such as quality, quantity, and price.

Traceability architecture design based on blockchain technology

- Based on the existing conditions that have been made, identification of business processes and activities that are more specifically focused on tracing the variables of critical problems that occur can be designed so that a scheme can be designed in the traceability architecture of the white crystal sugar agro-industrial supply chain system.

- Traceability architecture design is based on literature reviews (books, journals, reading articles related to supply chain and traceability) and conducting live discussions during the initial survey or through online discussions.

- Verification and validation of traceability architectural designs based on related statistical methods and including experts in decision making.

- Analyze the capabilities of the traceability scheme based on the requirements desired by an efficient supply chain system. Identification of integrated information flows data from upstream to downstream of the chain so that the data is timely and accurate.
Design a blockchain-based prototype based on traceability in the supply chain system with a description using UML. Based on the following steps:

- Designing and integrating transaction database information into the application architecture.

- User interface system design.

- Designing detailed blockchain-based prototypes.

- Verification and validation of blockchain-based prototypes based on traceability architecture.

- Initial trials before implementing the supply chain managerial system of white crystal sugar agro-industry.

Identification of the supply chain system configuration is based on the principles of the Supply Chain Operations Reference (SCOR) (Vorst 2014)[8], which is explained through four main elements, namely: a chain structure that describes the scope, roles of chain members and the agreements that make up the chain. A chain business process is a structured and measurable series of business activities to produce optimal output for consumers. Chain network management describes the coordination between actors in carrying out business processes in producing white crystal sugar products.

The condition of the existing system is based on a qualitative descriptive method that is supported by the opinions of sources, practitioners, initial field observations, and literature studies, and direct interviews through communication tools. The design of the supply chain system for white crystal sugar agro-industry will be modeled using the Unified Modeling Language (UML).

The prototype will be designed and implemented to facilitate transactions using the decentralized Ethereum Virtual Machine (EVM) system that allows tracking transactions between actors in the supply chain system, to build a reliable transparency process through the supply chain system from upstream to downstream to increase efficiency and productivity actors who play a role in the system as well as the quality of white crystal sugar products based on blockchain technology.

The system to be proposed is expected to provide transparency regarding the amount of production or availability of sugar cane, sugar, for each of the actors involved. Transparency in purchase prices among actors ranging from farmers to end consumers, and the quality of products in end consumers by improving their health and safety in consuming sugar according to the details of the composition of sugar contained in the packaging, coming from areas where sugarcane has been processed into white crystal sugar and also the date the expiry date. Whereas farmers can find out to what extent the sugarcane they plant and care for is consumed by consumers in which areas. So that the welfare of all actors involved in the supply chain system can be realized.

\section{ANALYSIS AND DisCUSSION}

The globalization of trade causes supply chains to become more complex, even when the real relationship between 
stakeholders is disharmony, and there is a lack of coordination, traceability of objects through the network is increasingly needed. Many sugar companies were forced to close due to fraud that occurred due to a lack of control over the production process, starting from the contract process with sugar cane farmers, the sugarcane weighing process, to the process of milling sugar cane into sugar.

However, there are also not a few sugar companies that still survive in producing sugar to remain stable and even get bigger due to financial support from the private sector. Delays and limitations in increasing inefficient supply chains, due to traditional flows and upstream to downstream data information transfers are still centralized. Inefficiencies that occur, such as the delivery of information that is often late and there is inequality of information received, dishonesty of data providers, and changing data arbitrarily so that companies cannot control the flow of information properly because the data is not real, not timely and reliable.

Traditional databases use a client-server network architecture. Here, the user (known as the client) can change the data, which is stored on a centralized server. Fixed database controls with defined authorities that authenticate client credentials before granting access to the database. This authority is in charge of database administration, if the security authorities are compromised, the data can be changed, or even deleted.

Fig. 3 explains the existing conditions that occur in the sugar agroindustry supply chain system. The main actors involved in the supply chain starting from farmers, operators of sugarcane yards (cutting and transporting), sugar factories, warehouses, corporate centers, distributors, retailers to consumers. While the general production process [30] is divided based on sections such as agronomy which contains data on contracts with farmers, land and agricultural classification data, charcoal data based on plantation area and area, sugarcane category and variety data, and data at the time of milling sugarcane per day.

In the hauling section, the available data are felling schedule data based on transport orders, transport data, data on the number of incoming and weighed sugarcane. On the scale, there is data on the net weight of sugarcane (net weight - the empty weight of the truck) and data on tare weight (weight of sugarcane transported by crane). Data on the milling and QC processes consist of data on the classification of quality of sugarcane-based on (physical, cleanliness) and sugar classification data based on SNI.

The data warehouse that is centralized at the head office consists of data on the amount of sugar production, production time data, price data, batch data, and logistics operators, while distributors send delivery orders as well as retailers and consumers consisting of data on quantity, time, the accuracy of delivery and order recipients.

The problems that occur in the supply chain of white crystal sugar agro-industry currently require transparency and traceability for the development of a sustainable supply chain. To integrate problems into one major problem, such as the conflict between chain actors caused by distrust, data corruption, or data forgery that can harm all actors, product safety, product defects during storage and packaging, and other problems. Therefore, the researcher proposes a blockchain-based sugar agro-industrial supply chain system design architecture as shown in Fig. 4 which has the advantage of tracking problems that occur in the supply chain to be resolved quickly, transparently, resiliently, and fairly. Because the distribution of data that has been recorded in the block cannot be changed without the consent of the consensus involved.

All of these problems will force us to explore with the right approach to trace the origin, distribution, product status, expiry time, distribution time, and storage along the long and complex sugarcane supply chain. This is because tracking the existence of sugarcane commodities until sugar products are consumed by consumers through the chain, can improve the relationship between upstream farmers and downstream consumers, and it is also expected to control the quality of products produced by sugar factories. 


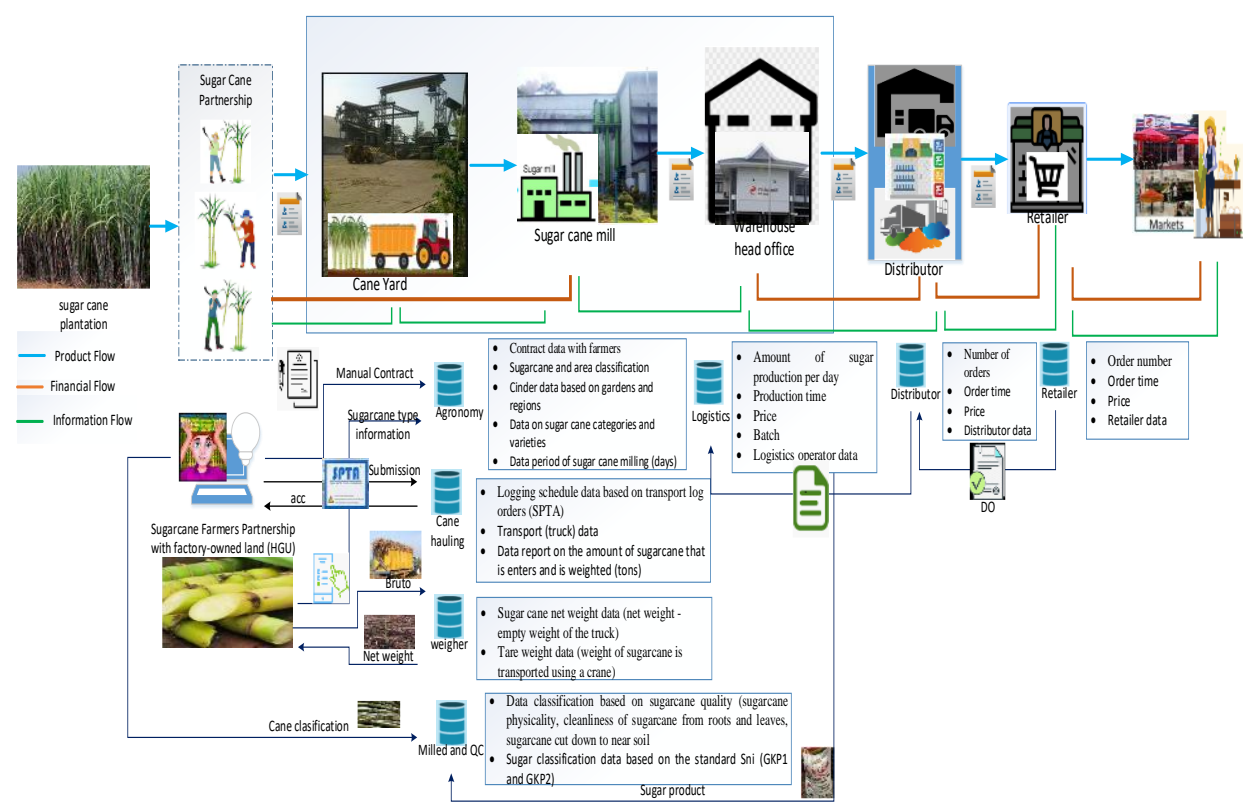

Fig. 3. The Existing Condition of the White Crystal Sugar Agroindustry Supply Chain System.

Farmer data Garden location Sugarcane varieties are planted Planting time Felling time

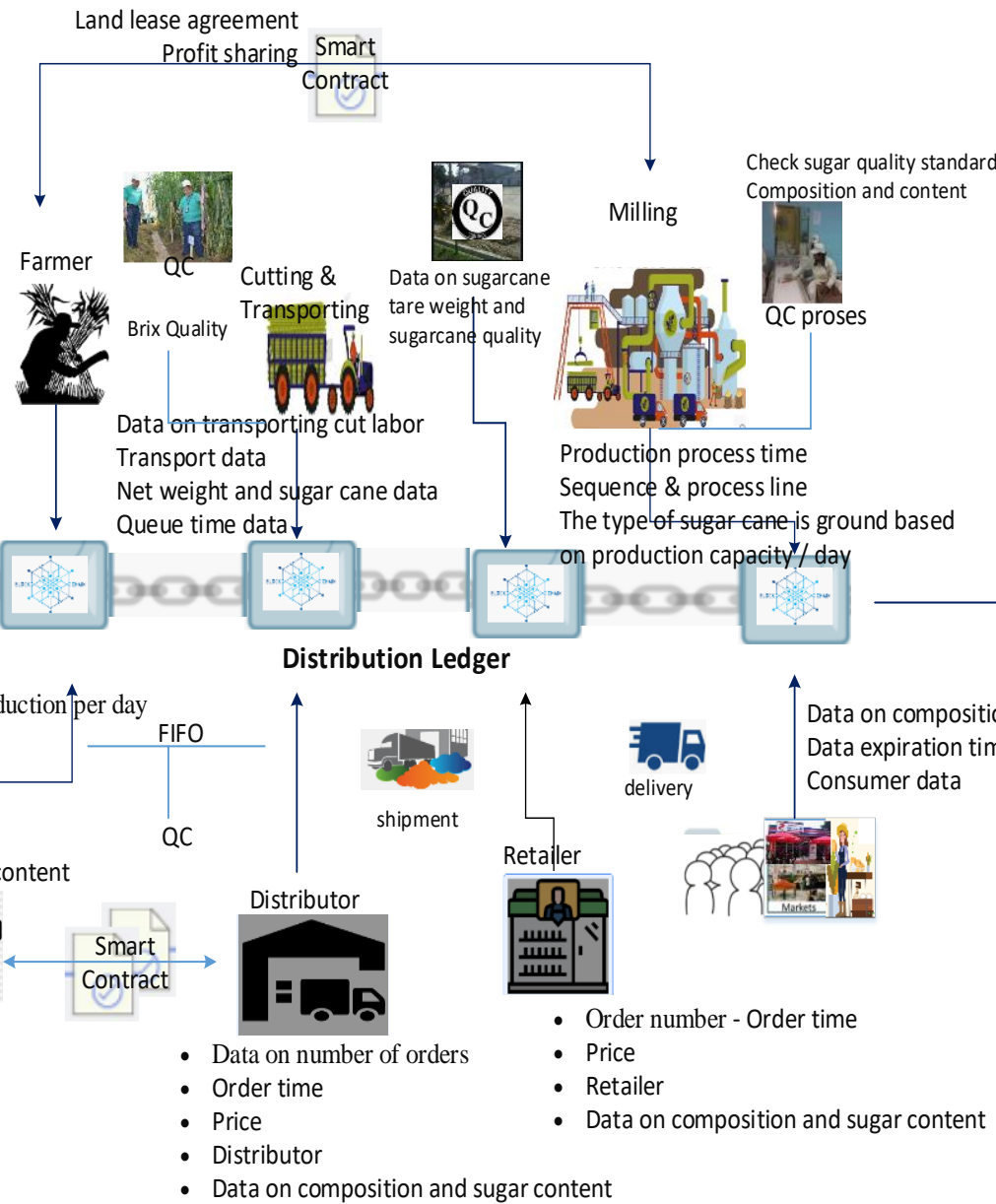

Fig. 4. Architectural Sugar Industrial Supply Chain based on Blockchain Technology.

How to solve traditional supply chain problems which are very sensitive and valuable for data trust and security, because in traditional and centralized systems we cannot prevent fraud and errors in data information flowing from upstream to downstream or from the data of additional actors (government and financial institutions) which can make it difficult for 
consumers to access and verify data sources[31]\&[32]. Under the proposed title is the design of a blockchain-based white crystal sugar agro-industrial supply chain system, in which the blockchain can help enable unprecedented transparency, safely throughout the supply chain that will eliminate fraud and errors, improve logistics performance and supply chain management, minimize costs, reduce waste and process delays. According to the estimates from IBM [33], blockchain can increase global GDP by nearly $5 \%$ and total trading volume by $15 \%$.

Blockchain is an unchanging and reliable shared ledger in storing transaction information of various data and actors in the supply chain. With a decentralized network and smart contracts, product information can be trusted, recorded securely, and does not change from upstream to downstream of the supply chain. The following is a proposal for designing a blockchain-based white crystal sugar agro-industry supply chain system.

Agroindustry supply chain which is globally inefficient, it is difficult to track problems that occur in the supply chain intentionally or unintentionally caused by corruption of data, product, and financial information that is not detected. The challenge of the supply chain now is to improve the data management functions that are still manual, centralized, data corruption, and data that are not real-time. Various efforts to improve supply chain performance become more efficient by increasing supply chain operations, to reduce the risks that occur.

Therefore, proposing the design of blockchain-based supply chain systems through the process of traceability and smart contracts is expected to improve the performance and competitiveness of the white crystal sugar agroindustry. So that it can benefit all actors in the supply chain and transparency and trust between actors can be increased as well.

Blockchain technology is expected to optimize supply chain performance, financing processes and accelerates process operations in the processing industry by providing safe, concise solutions, without using paper records and centralization. Can ease the manual process, ensure the accessibility, transparency, and integrity of the white crystal sugar agroindustry supply chain.

The blockchain network can also be applied in each of the supply chain actors so that it will form a reliable integrated information technology infrastructure and simplify workflow. Blockchain also facilitates accurate tracking of the quantity and quality of products along the chain to improve software performance, the performance of all actors in the supply chain network, which in turn can increase trust and transparency from the initial source until the product is consumed by the end consumers.

If these things are applied, the efficiency of supply chain performance will increase, intentional or unintentional mistakes will be reduced to zero defects and the benefits of actors along the chain can be maximized [34].

\section{CONCLUSION}

This research is expected to produce a design of a white crystal sugar agroindustry supply chain system based on blockchain technology. The previous traditional method which was still based on data centralization was changed to decentralized information, providing transparency and trust along with the supply chain actors with immutability based on cryptographic hash functions to secure data, tracking the truth of data quality, the quantity of inventory, and price, to provide product composition information. So that the blockchainbased traceability architecture design can be developed and implemented in white crystal sugar agroindustry by looking at the readiness of human, technological and financial resources. So that prototypes can be prepared based on the available blockchain consortium platforms such as Ethereum, by verifying and validating the supply chain system.

The suggestion raised is that this design can be made with a local platform that is starting to develop, such as the Vexanium Indonesia public blockchain, which has speeds above 2000 transactions per second and according to programmers is more suitable for retail use and users dealing directly with consumers such as social media activists.

\section{ACKNOWLEDGMENT}

This research received financial support from BUDI DN LPDP. I would like to thank the three supervisory commissions, IPB University who has provided knowledge, input, and suggestions for initial research on the sugar agroindustry, blockchain technology. I also want to thank my family (husband, children, and parents) who have supported my research.

\section{REFERENCES}

[1] K. Pertanian, "Regulation of the Minister of Agriculture of the Republic of Indonesia No.68 / Permentan / OT.140 / 6/2013,” 2013.

[2] M. Asrol, M. Marimin, and M. Machfud, "Supply Chain Performance Measurement and Improvement for Sugarcane Agro-industry," Int. J. Supply Chain Manag., vol. 6 No.3, no. September, pp. 8-21, 2017.

[3] H. Suliantoro and D. Nugrahani, "Measurement and Evaluation of Supply Chain Performance Using the Balanced Scorecard-Analytical Network Process (BSC-ANP) Approach at PT.Madubaru Yogyakarta," in SNST Proceeding, 2015, pp. 17-23.

[4] A. F. Fadhilah et al., "Performance Efficiency of Ant Sugar Supply Chain CV. Incised Politan in Kulon Progo Regency," JoFSA, vol. 1, no. 2, pp. 60-70, 2017.

[5] A. M. Khushk, S. Sciences, A. Memon, and I. Saeed, "Analysis of sugar industry competitiveness in Pakistan," J. Agric. Res., vol. 49(1), no. November, pp. 137-155, 2015.

[6] D. J. Garcia and F. You, "Supply chain design and optimization: Challenges and opportunities," Comput. Chem. Eng., vol. 81, pp. 153$170,2015$.

[7] P. Stutterheim, "An Integrated Sugarcane Supply Chain Model: Development and Demonstration," University of KwaZulu-Natal, 2006.

[8] J. Van Der Vorst, Performance measurement in agri-food supply-chain networks - An overview, no. January 2006. 2014.

[9] M. Aravendan and R. Panneerselvam, "Literature review on network design problems in closed-loop and reverse supply chains," Intell. Inf. Manag., no. May, pp. 104-117, 2014.

[10] J. Jonkman, A. Kanellopoulos, and J. M. Bloemhof, "Designing an ecoefficient biomass-based supply chain using a multi-actor optimization model," J. Clean. Prod., vol. 210, pp. 1065-1075, 2019.

[11] A. Cheraghalipour, M. M. Paydar, and M. Hajiaghaei-Keshteli, "Designing and solving a bi-level model for rice supply chain using the 
evolutionary algorithms," Comput. Electron. Agric., vol. 162, no. March, pp. 651-668, 2019.

[12] N. Chiadamrong and R. Kawtummachai, "A methodology to support decision-making on sugar distribution for export channel: A case study of the Thai sugar industry," Comput. Electron. Agric., vol. 64, no. 2, pp. 248-261, 2008.

[13] L. U. Opara, "Traceability in agriculture and food supply chain: A review of basic concepts, technological implications, and prospects," J. Food Agric. Environ., vol. 1, no. (1), pp. 101-106, 2003.

[14] M. M. Aung and Y. S. Chang, "Traceability in a food supply chain: Safety and quality perspectives," Food Control, vol. 39, pp. 172-184, 2014.

[15] M. Fritz and G. Schiefer, "Tracking, tracing, and business process interests in food commodities: A multi-level decision complexity," Int. J. Prod. Econ., vol. 117, no. 2, pp. 317-329, 2009.

[16] G. B. Zhang, Y. Ran, and X. L. Ren, "Study on product quality tracing technology in the supply chain," Comput. Ind. Eng., vol. 60, no. 4, pp. 863-871, 2011.

[17] G. Barilla, A. Pinna, and G. Corrias, "Ensure Traceability in European Food Supply Chain by using a blockchain System," in WETSEB2019, 2019, no. March, pp. 1-8.

[18] S. Charlebois, M. Juhasz, L. Foti, and S. Chamberlain, "Food Fraud and Risk Perception: Awareness in Canada and Projected Trust on riskmitigating Agents," J. Int. Food Agribus. Mark., vol. 29, no. 3, pp. 260277, 2017.

[19] M. V. Kumar and N. C. S. N. Iyengar, "A Framework for Blockchain Technology in Rice Supply Chain Management Plantation," in Advanced Science and Technology Letters, 2018, no. vol 146, pp. 125130.

[20] P. Helo and A. H. M. Shamsuzzoha, "Real-time supply chain-A blockchain architecture for project deliveries," Robot. Comput. Integer. Manuf., vol. 63, pp. 1-14, 2020.

[21] R. Casado-vara et al., "How blockchain improves supply the supply chain : case study alimentary chain supply chain supply chain," Procedia Comput. Sci., vol. 134, pp. 393-398, 2018.

[22] G. Zhao et al., "Blockchain technology in agri-food value chain management: A synthesis of applications, challenges, and future research directions,” Comput. Ind., vol. 109, pp. 83-99, 2019.
[23] V. Thiruchelvam, A. S. Mughisha, M. Shahpasand, and M. Bamiah, "Blockchain-based Technology in the Coffee Supply Chain Trade : Case of Burundi Coffee," J. Telecommun. Electron. Comput. Eng., vol. 10, no. 3-2, pp. 121-125, 2018.

[24] K. Salah, N. Nizamuddin, R. Jayaraman, and M. Omar, "BlockchainBased Soybean Traceability in Agricultural Supply Chain," IEEE Access, vol. 7, pp. 73295-73305, 2019.

[25] G. Perboli, S. Musso, and M. Rosano, "Blockchain in Logistics and Supply Chain: A Lean Approach for Designing Real-World Use Cases," IEEE Access, vol. XX, pp. 1-12, 2018.

[26] A. A. Arsyad, S. Dhadkah, and M. Koppen, "Two-Factor Blockchain for Traceability Cacao Supply Chain," springer Nat. Switz. Ag, vol. 23, pp. 332-339, 2019.

[27] F. Tian, "An agri-food supply chain traceability system for China based on RFID \& blockchain technology," in 13th International Conference on Service Systems and Service Management, 2016, pp. 1-6.

[28] J. F. Galvez, J. C. Mejuto, and J. Simal-Gandara, "Future challenges on the use of blockchain for food traceability analysis," Trends Anal. Chem., pp. 1-43, 2018.

[29] H. Feng, X. Wang, Y. Duan, J. Zhang, and X. Zhang, "Applying blockchain technology to improve agri-food traceability: A review of development methods, benefits, and challenges," J. Clean. Prod., vol. 260, 2020.

[30] W. A. Kusumo, Y. Setiowati, and K. Fathoni, "The design of information system for sugar cane milling in a sugar company as a case study of the new pesantren sugar factory-Kediri," 2013.

[31] S. Abeyratne and R. . Monfared, "Blockchain ready manufacturing supply chain using a distributed ledger," Int. J. Res. Eng. Technol., vol. 05, no. 09, pp. 1-10, 2016.

[32] P. Helo and Y. Hao, "Blockchains in operations and supply chains: A model and reference implementation," Comput. Ind. Eng., vol. 136, no. July, pp. 242-251, 2019.

[33] M. H. Ronaghi, "A blockchain maturity model in the agricultural supply chain,” Inf. Process. Agric., pp. 1-10, 2020.

[34] E. Chen, "An approach for Improving Transparency and Traceability of Industrial Supply Chain with Blockchain Technology," Tampere University of Technology, 2016. 